\title{
Identification of uropathogenic Escherichia coli clonal group A (CgA) in hospitalised patients
}

\author{
Rubens CS Dias', Denise V Marangoni², Lee W Riley ${ }^{1}$, Beatriz M Moreira ${ }^{3}{ }^{+}$ \\ ${ }^{1}$ School of Public Health, University of California, Berkeley, CA, USA ${ }^{2}$ Faculdade de Medicina ${ }^{3}$ Instituto de Microbiologia, Centro de Ciências \\ da Saúde, Universidade Federal do Rio de Janeiro, Cidade Universitária Bloco I, 21941-590 Rio de Janeiro, RJ, Brasil
}

This study provides the first description of healthcare-associated infections with Escherichia coli clonal group A (CgA) isolates in Latin America. Isolates were typed by enterobacterial repetitive intergenic consensus-PCR, pulsed-field gel electrophoresis, E. coli phylogenetic grouping, multilocus sequence typing and fimH single nucleotide polymorphism analysis. Out of $42 \mathrm{E}$. coli hospital isolates studied, three belonged to E. coli phylogenetic group $D$ and ST69 and had fimH sequences identical to that of the $C g A$ reference strain ATCC BAA-457. E. coli $C g A$ is another potential source of resistant infections in hospitals.

Key words: community E. coli clonal group - hospital infections - antimicrobial resistance

In 2001, Manges et al. (2001) identified an Escherichia coli clonal group A ( $\mathrm{CgA})$ designated based on enterobacterial repetitive intergenic consensus (ERIC)PCR electrophoretic banding pattern. $\mathrm{CgA}$ isolates accounted for up to $50 \%$ of trimethoprim-sulfamethoxazole (SXT)-resistant $E$. coli isolated from women with acute uncomplicated urinary tract infections (UTI) in one university community (Manges et al. 2001). CgA isolates have been recovered from women in the United States with cystitis, pyelonephritis and bloodstream infections (Manges et al. 2001, 2004, Johnson et al. 2002, Petrof et al. 2002). CgA isolation has also been described in other parts of the world (Johnson et al. 2005, Manges et al. 2008). The isolates in Latin America studied to date were found among a collection of 60 E. coli isolates of unknown origin in Curitiba, state of Paraná, Brazil. CgA was found in three urine isolates by random amplification of polymorphic DNA and phylogenetic grouping analyses (Johnson et al. 2005).

In the present report, we describe the identification of three $\mathrm{CgA}$ E. coli isolates from a public university-affiliated hospital in Rio de Janeiro, Brazil, exhibiting the four predominant ERIC-PCR bands of approximately $1145,1029,908$ and $720 \mathrm{bp}$ that are typically observed for $\mathrm{CgA}$ (Manges et al. 2001). These isolates were further characterised as described below.

Initially, E. coli isolates were evaluated by ERICPCR and pulsed-field gel electrophoresis (PFGE), as previously described (Bender et al. 1997, Dias et al. 2008). Briefly, for ERIC-PCR, amplifications were carried out

Financial support: CNPq, CAPES, FAPERJ, Fogarty International Program in Global Infectious Diseases (TW006563) of National Institutes of Health (AI059523)

+ Corresponding author: bmeurer@micro.ufrj.br

Received 2 January 2009

Accepted 26 June 2009 in a total volume of $25 \mu \mathrm{L}$. Each reaction contained buffer, $0.1 \mathrm{mM}$ of each dNTP, $3 \mathrm{mM} \mathrm{MgCl}, 0.3 \mu \mathrm{M}$ ERIC2 primer (5'-AAGTAAGTGACTGGGGTGAGCG-3'), 1.5 U Taq DNA polymerase (BIOTOOLS) and $3 \mu \mathrm{L}$ template DNA. Reaction conditions were as follows: a 2 min initial denaturation at $94^{\circ} \mathrm{C}$ followed by 40 cycles of a $30 \mathrm{sec}$ denaturation at $94^{\circ} \mathrm{C}$, a $1 \mathrm{~min}$ annealing at $54^{\circ} \mathrm{C}$ and a 4 min extension at $72^{\circ} \mathrm{C}$ and a final extension step of $1 \mathrm{~min}$ at $72^{\circ} \mathrm{C}$. Amplification products were electrophoresed on $1.5 \%$ agarose gels. For PFGE, chromosomal DNA in the plugs was digested with $\mathrm{Xba \textrm {I }}$ (New England BioLabs) at $37^{\circ} \mathrm{C}$ according to the instructions of the manufacturer. The restriction fragments were separated by PFGE on $1 \%$ agarose gels and electrophoresis was carried out in a CHEF DR II system (Bio-Rad Laboratories) at $13^{\circ} \mathrm{C}$ and $6 \mathrm{~V} / \mathrm{cm}$ for $22 \mathrm{~h}$ with pulse times ranging from 2.2-54.2 sec. DNA-banding patterns were interpreted by visual inspection and with the GelCompar II program version 4.01 (Applied Maths, Sint-Martens-Latem, Belgium). The CgA reference strain ATCC BAA-457 was included for comparison in all experiments.

For phylogenetic analysis, E. coli phylogrouping (A, $\mathrm{B} 1, \mathrm{~B} 2$ or D) was assessed using a previously reported triplex PCR-based assay (Clermont et al. 2000). In addition, multilocus sequence typing (MLST) was performed using a standardised protocol for E. coli maintained at the MLST Databases at the ERI, University College Cork website (http://mlst.ucc.ie/). Briefly, amplifications were carried out in a total volume of $50 \mu \mathrm{L}$. Each reaction contained buffer, $0.2 \mathrm{mM}$ of each dNTP, $1.5 \mathrm{mM} \mathrm{MgCl}, 0.2 \mu \mathrm{M}$ of each primer, $2.5 \mathrm{U}$ AmpliTaq Gold (Applied Biosystems) and $2 \mu \mathrm{L}$ template DNA. Reaction conditions were as follows: a 2 min initial denaturation at $95^{\circ} \mathrm{C}$ followed by 30 cycles of a $1 \mathrm{~min}$ denaturation at $95^{\circ} \mathrm{C}$, a $1 \mathrm{~min}$ annealing at the temperature specified for each gene (http://mlst.ucc.ie/) and a $2 \mathrm{~min}$ extension at $72^{\circ} \mathrm{C}$ and a final extension step of $5 \mathrm{~min}$ at $72^{\circ} \mathrm{C}$. fim $H$ single nucleotide polymorphism analysis was performed as reported previously (Tartof et al. 2007) with modifications. Primers used for PCR amplification and partial fim $H$ gene sequencing were FimH-f 
(5'-CGAGTTATTACCCTGTTTGCTG-3') and FimH-r (5'-ACGCCAATAATCGATTGCAC-3'). Both strands of the 878 bp PCR-amplified fragment were sequenced. After visual inspection and editing with BioEdit version 7.0.9.0, fragments of $424 \mathrm{bp} \mathrm{fim} \mathrm{H}$ sequences (located at bp 401-824 of E. coli sequence accession \#NC000913, GenBank) were compared to the $\mathrm{CgA}$ reference sequence.

The three putative $\mathrm{CgA}$ strains were recovered from three female patients older than 45 years of age with healthcare-associated infections. Two isolates (Fer137 and Fer204) were obtained from the urine of patients with symptomatic (fever without any other identifiable causes and/or abdominal pain) UTI. One isolate was from a transplant patient with a bladder catheterassociated UTI and the other from a patient admitted to investigate a respiratory disease, but without a urinary catheter. The third isolate (Fer189) was obtained from a blood culture of a patient with collagen disease. This patient had a central vascular catheter in place and the bloodstream infection was considered to be a central vascular catheter-associated infection. All patients were admitted to the hospital between May 11-29 2001 and the $E$. coli isolates were recovered 6-20 days after admission. The three isolates were detected as SXT and cephalothin-resistant by disk diffusion testing (CLSI 2009) and they exhibited indistinguishable ERIC2-PCR and PFGE band patterns. The ERIC2-PCR band patterns of the isolates were also indistinguishable from that of the CgA reference strain ATCC BAA-457 (100\% similarity), whereas the PFGE patterns of the isolates showed four band differences compared to the reference strain

A

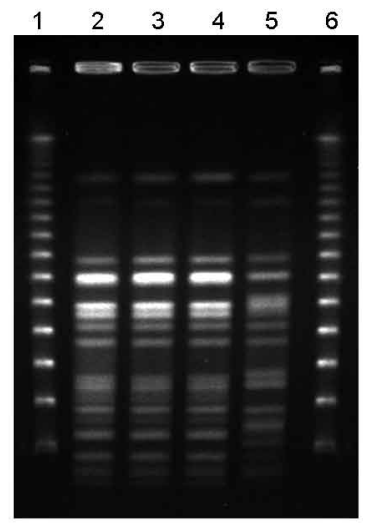

B

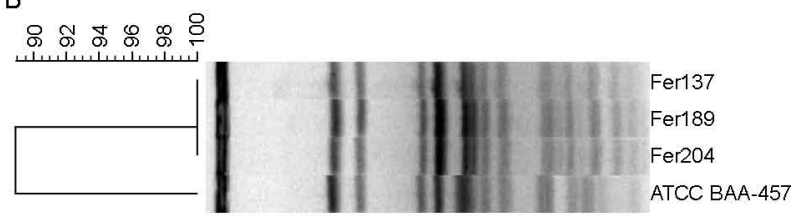

A: XbaI pulsed-field gel electrophoresis (PFGE) fingerprints of clonal group A (CgA) Escherichia coli isolates from Hospital Universitário Clementino Fraga Filho, Rio de Janeiro, Brasil. Lanes 1, 6: lambda ladder marker; 2-4: isolates Fer137, Fer189 and Fer204; 5: CgA reference strain ATCC BAA-457; B: dendrogram from computer assisted analyses of PFGE profiles in A.
(89\% similarity) (Figure). All isolates belonged to $E$. coli phylogroup D and ST69 by MLST and had identical fimH sequence to $\mathrm{CgA}$ reference strain. The reference strain ATCC BAA-457 also belongs to phylogroup D and ST69 (Tartof et al. 2005).

This is the first time E. coli $\mathrm{CgA}$ has been detected in patients in Rio de Janeiro, Brazil, and the first confirmed case of healthcare-associated $\mathrm{CgA}$ infections in Latin America. The possible sources of $\mathrm{CgA}$ in Brazil are unknown. It has been suggested that $\mathrm{CgA}$ can be spread by contaminated food (Manges et al. 2007) and its presence in sewage effluents may provide an additional source (Boczek et al. 2007). We believe a common source or cross-transmission of the CgA probably occurred among the three patients in the hospital because they were clustered in place and time and the isolates had identical PFGE patterns. PFGE bands may change in short periods of time (Tenover et al. 1995); therefore, the finding of identical patterns strongly suggests a close common ancestor. However, since $\mathrm{CgA}$ is a community pathogen, we cannot exclude the possibility that patients already had $\mathrm{CgA}$ isolates in their own microflora before admission, acquired from a community source.

$\mathrm{CgA}$ E. coli isolates have been shown to harbour integron-borne resistance gene cassettes, including the recently identified dihydrofolate-reductase $d f r l 7$ gene (France et al. 2005, Solberg et al. 2006). CgA in Rio de Janeiro, especially in a healthcare setting, may facilitate dissemination of these resistance genes and serve as yet another source of resistant infections in our hospitals as well as in our community.

\section{REFERENCES}

Bender JB, Hedberg CW, Besser JM, Boxrud DJ, MacDonald KL, Osterholm MT 1997. Surveillance for Escherichia coli O157:H7 infections in Minnesota by molecular subtyping. $N$ Engl J Med 337: 388-394.

Boczek LA, Rice EW, Johnston B, Johnson JR 2007. Occurrence of antibiotic-resistant uropathogenic Escherichia coli clonal group A in wastewater effluents. Appl Environ Microbiol 73: 4180-4184.

Clermont O, Bonacorsi S, Bingen E 2000. Rapid and simple determination of the Escherichia coli phylogenetic group. Appl Environ Microbiol 66: 4555-4558.

CLSI - Clinical and Laboratory Standards Institute 2009. Performance standards for antimicrobial susceptibility testing. Nineteenth Informational Supplement, CLSI document M100-S19, Clinical and Laboratory Standards Institute, Wayne, p. 1-149.

Dias RCS, Borges-Neto AA, Ferraiuoli GID’A, De-Oliveira MP, Riley LW, Moreira BM 2008. Prevalence of AmpC and other betalactamases in enterobacteria at a large urban university hospital in Brazil. Diagn Microbiol Infect Dis 60: 79-87.

France AM, Kugeler KM, Freeman A, Zalewski CA, Blahna M, Zhang L, Marrs CF, Foxman B 2005. Clonal groups and the spread of resistance to trimethoprim-sulfamethoxazole in uropathogenic Escherichia coli. Clin Infect Dis 40: 1101-1107.

Johnson JR, Manges AR, O'Bryan TT, Riley LR 2002. A disseminated multi-drug resistant clonal group of extraintestinal pathogenic $E s$ cherichia coli as a cause of pyelonephritis. Lancet 359: 2249-2251.

Johnson JR, Murray AC, Kuskowski MA, Schubert S, Prère M-F, Picard B, Colodner R, Raz R, the Trans-Global Initiative for Antimicrobial Resistance Analysis (TIARA) Investigators 2005. 
Distribution and characteristics of Escherichia coli clonal group A. Emerg Infect Dis 11: 141-145.

Manges AR, Dietrich PS, Riley LW 2004. Multidrug-resistant Escherichia coli clonal groups causing community-acquired pyelonephritis. Clin Infect Dis 38: 329-334.

Manges AR, Johnson JR, Foxman B, O’Bryan TT, Fullerton KE, Riley LW 2001. Widespread distribution of urinary tract infections caused by a multidrug-resistant Escherichia coli clonal group. N Engl J Med 345: 1007-1013.

Manges AR, Smith SP, Lau BJ, Nuval CJ, Eisenberg JNS, Dietrich PS, Riley LW 2007. Retail meat consumption and the acquisition of antimicrobial resistant Escherichia coli causing urinary tract infections: a case-control study. Foodborne Pathog Dis 4: 419-431.

Manges AR, Tabor H, Tellis P, Vincent C, Tellier P-P 2008. Endemic and epidemic lineages of Escherichia coli that cause urinary tract infections. Emerg Infect Dis 14: 1575-1583.
Petrof EO, Schwartz DN, Quinn JP 2002. Urinary tract infections and a multidrug-resistant Escherichia coli clonal group. $N$ Engl J Med 346: 535.

Solberg OD, Ajiboye RM, Riley LW 2006. Origin of class 1 and 2 integrons and gene cassettes in a population-based sample of uropathogenic Escherichia coli. J Clin Microbiol 44: 1347-1351.

Tartof SY, Solberg OD, Manges AR, Riley LW 2005. Analysis of a uropathogenic Escherichia coli clonal group by multilocus sequence typing. J Clin Microbiol 43: 5860-5864.

Tartof SY, Solberg OD, Riley LW 2007. Genotypic analyses of uropathogenic Escherichia coli based on fimH single nucleotide polymorphisms (SNPs). J Med Microbiol 56: 1363-1369.

Tenover FC, Arbeit RD, Goering RV, Mickelsen PA, Murray BE, Persing DH, Swaminathan B 1995. Interpreting chromosomal DNA restriction patterns produced by pulsed-field gel electrophoresis: criteria for bacterial strain typing. J Clin Microbiol 33: 2233-2239. 